\title{
Congenital Osseous Anomalies of the Cervical Spine: Occurrence, Morphological Characteristics, Embryological Basis and Clinical Significance: A Computed Tomography Based Study
}

\author{
N. V. Ankith, M. Avinash, K. S. Srivijayanand, Ajoy Prasad Shetty, \\ Rishi Mugesh Kanna, Shanmuganathan Rajasekaran \\ Department of Spine Surgery, Ganga Medical Centre \& Hospital Pvt. Ltd., Coimbatore, India
}

\begin{abstract}
Study Design: Observational retrospective computed tomography (CT) based study.
Purpose: To analyze the congenital anomalies of the cervical spine, their morphological variations and their clinical significance.

Overview of Literature: Studies published to date have focused mainly on upper cervical anomalies; no study has comprehensively reported on anomalies of both the occipitocervical and subaxial cervical spine.

Methods: Nine hundred and thirty cervical spine CT scans performed in Ganga Hospital, Coimbatore, India between January 2014 and November 2017 were screened by two independent observers to document anomalies of both the upper and lower cervical spine. CT scans conducted for infection, tumor, and/or deformity were excluded. Different morphological variations, embryological basis, and clinical significance of the anomalies were discussed.

Results: Of the 930 CT scans screened, 308 (33.1\%) had congenital anomaly. Of these, 184 (59.7\%) were males and 124 (40.2.7\%) were females, with a mean age of 44.2 years (range, 14-78 years). A total of 377 anomalies were identified, with 69 cases $(7.4 \%)$ having more than one anomaly. Two hundred and fifty (26.8\%) anomalies of the upper cervical region (occiput to C2-C3 disk space) were identified, with the most common upper cervical anomalies being high-riding vertebral artery (108 cases, 11.6\%) and ponticulus posticus (PP) (75 cases, 8\%). One hundred and twenty seven (13.6\%) anomalies of the lower cervical spine (C3-C7) were noted, of which double foramen transversarium was the most common anomaly observed in 46 cases $(4.8 \%)$.

Conclusions: We found that $33.1 \%$ of CT scans had at least one congenital anomaly. Some anomalies, such as abnormal facet complex and arch anomalies, have to be differentiated from fractures in a trauma patient. Other anomalies, like PP, have to be looked for during preoperative planning to avoid complications during surgery. Therefore, knowledge of these anomalies is important as different anomalies have different clinical courses and management.
\end{abstract}

Keywords: Congenital; Morphology; Anomaly; Developmental; Spine

\footnotetext{
Received Oct 1, 2018; Revised Nov 8, 2018; Accepted Nov 14, 2018

Corresponding author: Ajoy Prasad Shetty

Department of Orthopaedics and Spine Surgery, Ganga Medical Centre \& Hospital Pvt. Ltd., \#313, Mettupalayam Road, Sai Baba Colony, Coimbatore, Tamil Nadu 641001, India

Tel: +91-9344833797, Fax: +91-422-2485000, E-mail: ajoyshetty @gmail.com
} 


\section{Introduction}

The spine is a unique anatomical structure, and the cervical spine is even more unique due to the complex mechanisms involved in its formation. Anomalies of the cervical spine can range from simple fused vertebrae due to segmentation defect or complex craniocervical instability. Embryologically the upper cervical spine, which extends between occiput and the $\mathrm{C} 2-\mathrm{C} 3$ disk space, is different from the rest of the subaxial cervical spine. Anomalies of the upper cervical spine cause early symptoms in life due to their propensity to develop segmental instability and consequent spinal canal encroachment leading to neurological deficits. In contrast, lower cervical anomalies become symptomatic in adulthood due to degenerative arthritis at the hypermobile articulations adjacent to the site of synostosis. A thorough evaluation of these anomalies, such as unfused clivus (UC), abnormal facet complex (AFC), and accessory ossicles, is of utmost importance as they can cause diagnostic difficulties in the context of traumatic spinal injuries, whereas anomalies like ponticulus posticus (PP) and arch anomalies have a significant bearing on surgical planning. Previous studies [1-3] have focused mainly on pediatric upper cervical anomalies and single anomalies [4-10]. To our knowledge, there is no study which has comprehensively reported on anomalies of both the occipitocervical (OC) and sub axial cervical spine. The objectives of this study are to: (1) determine the presence of congenital anomalies in a cohort of patients; and (2) outline the clinical and surgical significance of such anomalies.

\section{Materials and Methods}

With the approval from the institutional review board (IRB approval no., 2018/09/06), cervical spine computed tomography (CT) scans (Somatom Sensation 64 slices; Siemens, Berlin, Germany) of 930 patients taken between January 2014 and November 2017 were analyzed. Informed consent is not required as it is a radiological study. The scans were taken from patients who presented with cervical spine trauma or cervical myelopathy. Patients with deformities, infection, or tumors were excluded. Sagittal, coronal, and axial sections of the CT scans were screened by two individual observers, and a consensus was reached before documenting the anomaly.

Cervical spine anomalies were divided into upper cervical (occiput to the $\mathrm{C} 2-\mathrm{C} 3$ disk) and subaxial. Upper cer- vical anomalies included OC anomalies like UC, occipitoatlantal assimilation (OA), basilar invagination (BI), platybasia (PB), accessory OC articulation/paracondylar process (AOCA), prebasioccipital arch (PBA), and condylus tertius (CDT). C1 anomalies such as PP, accessory ossicle of atlas (AOA), and arch anomalies were included. C2 anomalies, namely odontoid anomalies (os odontoideum, ossiculum terminale), high riding vertebral artery (HRVA) of C2 (defined as an internal height $<2 \mathrm{~mm}$ and isthmus height $<5 \mathrm{~mm}$ on sagittal images) [11], and arch anomalies were recorded.

Anomalies of the subaxial cervical spine, including vertebral fusion (VF), unfused spinous process (USP), double foramen transversarium (DFT), cervical rib (CR), and AFC were recorded. A brief note on the developmental anatomy of the cervical spine and the embryological basis for the occurrence of the anomaly is also mentioned.

\section{Developmental anatomy of the cervical spine}

The paraxial mesodermal tissue around the notochord differentiates into somites, which subsequently repartition into 4 occipital, 8 cervical, 12 thoracic, 5 lumbar, 5 sacral, and 8-10 coccygeal somites. During resegmentation, these somites give rise to sclerotomes. The caudal half of the fourth occipital somite and rostral half of the fifth somite combine to form the proatlas sclerotome (PA). The axial zones of the proatlas gives rise to the basion of the basiocciput (or clivus), and the apical segment of the dens, the lateral zones of the proatlas develops into the occipital condyle, lateral rim, and opisthion of the foramen magnum. Both the caudal half of the fifth somite, and the sixth somite contribute to the formation of the $\mathrm{C} 1$ sclerotome. The axial zones of the $\mathrm{C} 1$ sclerotome $(\mathrm{C} 1 \mathrm{~A})$ form the basal segment of the dens, whereas the lateral zone (C1L) forms the posterior atlantal arch. The hypochordal bow of the $\mathrm{C} 1$ sclerotome forms the anterior atlantal arch. The sixth and seventh somites form the $\mathrm{C} 2$ sclerotome, the axial zone forms the body of the $\mathrm{C} 2$ vertebra, and the lateral zones give rise to the posterior arch of the $\mathrm{C} 2$ vertebra [4] (Fig. 1). Following are the reported anomalies and their embryological basis.

\section{Anomalies of the basiocciput and $\mathrm{C} 1$}

1) Occipital vertebrae

Incomplete assimilation of the caudal occipital somite and 


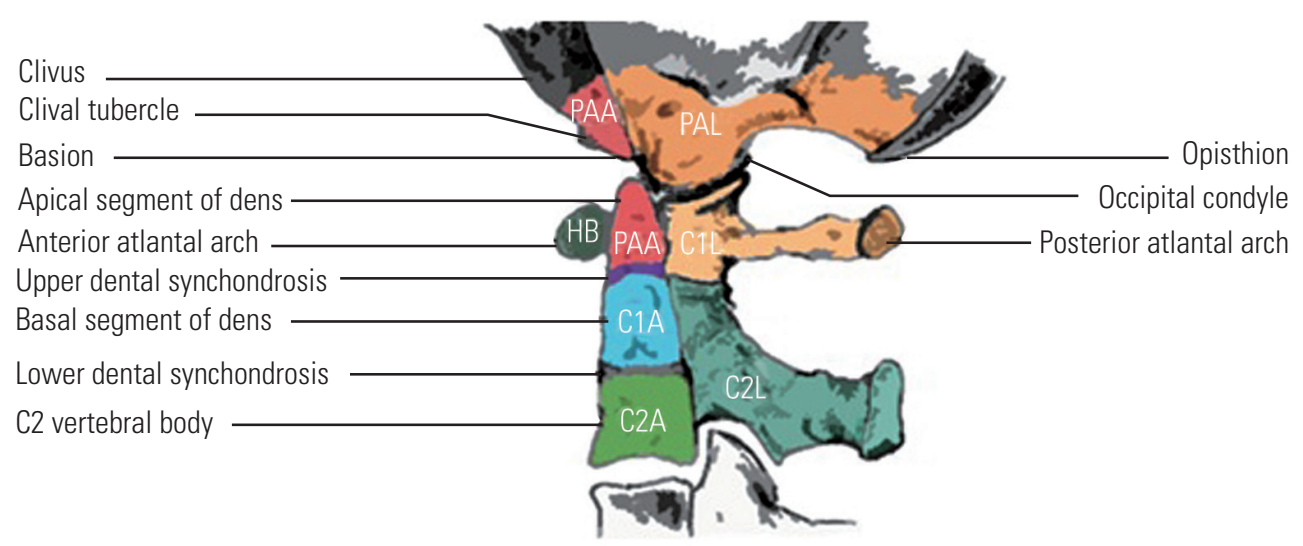

Fig. 1. Development of the craniovertebral junction. The sclerotomes and corresponding regions, which they give rise to are depicted. PAA, axial zone of proatlas; PAL, lateral zone of proatlas; HB, hypochondral bow; C1A, axial zone of C1 sclerotome; C1L, lateral zone of C1 sclerotome; C2A, axial zone of C2 sclerotome; C2L, lateral zone of C2 sclerotome.

rostral portion of the first cervical sclerotome results in a variety of manifestations collectively referred to as 'occipital vertebrae.' The four variants of the occipital vertebrae are as follows:

(1) Prebasioccipital arch

The bony projection on the ventral lip of the anterior foramen magnum rim formed due to complete preservation of the hypochordal bow of the proatlas.

(2) Third occipital condyle/condylus tertius

Attached to the ventral surface of the clival tip and fuzed to the anterior atlantal arch, this anomaly is formed due to hyperplasia of the proatlas hypochondral bow.

\section{(3) Paracondylar process}

The bony projection that arises from the paracondylar area of the occiput articulating with the superior surface of the transverse process of the atlas.

\section{(4) Basilar processes}

Basilar processes are dome-shaped bony protrusions near the anterior margins of the occipital condyles.

\section{2) Unfused clivus}

The clivus, or lower basioccipital segment, is unfused to the upper basioccipital segment. In some cases, the dens may be fuzed to the anterior $\mathrm{C} 1 \mathrm{arch}$ as if the atlas is acquiring its own centrum.
3) C1 assimilation/occipitalization of the atlas

Ranges from complete incorporation of the atlas into the occiput to discrete osseous bridges between the atlas and occiput. It develops due to non-resegmentation of the PA sclerotome.

\section{4) Basilar invagination}

An anomaly where the vertebral column is abnormally high and prolapses into the skull base. Identification was based on the Chamberlain's line between the hard palate and opisthion [12], which considers BI if the tip of the dens is $>2.5 \mathrm{~mm}$ above this line.

\section{Anomalies involving only the $\mathrm{C} 1$ vertebra}

1) $\mathrm{C} 1$ arch anomalies

Aplasia/hypoplasia of the $\mathrm{C} 1$ hypochordal bow. Complete aplasia of the hypochondral bow of the $\mathrm{C} 1$ sclerotome results in an absent $\mathrm{C} 1 \mathrm{arch}$; insertion tubercles of the transverse atlantal ligament are either greatly attenuated or non-existent, resulting in C1-C2 instability. Similarly, aplasia/hypoplasia of the lateral $\mathrm{C} 1$ sclerotome causes posterior arch anomalies.

\section{2) Accessory ossicle of the atlas}

An irregular fragment located inferior to the anterior arch of the atlas, which develops from the accessory ossification center for the anterior arch of the atlas. Clear cortical margins and characteristic location helps to differentiate this variant from a fracture. 
3) Ponticulus posticus

An anomalous malformed bony bridge between the posterior portion of the superior articular process and the posterolateral portion of the superior margin of the posterior arch of the atlas. Exact etiology is unknown; however, it may be congenital [13] or age related [14] due to ossification associated with aging.

\section{Anomalies of the $\mathrm{C} 2$ vertebra}

\section{1) Ossiculum terminale persistens}

This anomaly, also called as Bergman ossicle, is a, small, isolated, rounded bone near the tip of the dens axis, usually in continuation of the vertical axis of the odontoid bone due to failed fusion of the terminal ossicle to the remainder of the odontoid process (the central pillar of the craniovertebral junction). However, the dens is not deficient, and resultantly this anomaly is of little clinical significance.

\section{2) Os odontoideum}

An independent osseous structure lying cephalad to the axis body in the location of the odontoid process, resulting from the disturbance of the intervertebral boundary mesenchyme of the proatlas and first two cervical sclerotomes.

\section{Subaxial cervical anomalies}

\section{1) Double foramen transversarium}

Foramen transversarium is formed by the vestigial costal element, fuzed to the body and the true transverse process of the vertebra. Variations in the presence and course of the vertebral vessels may manifest as variations of the foramina transversarium.

\section{2) Cervical rib}

Failure of resorption of the ossified C7 lateral costal element results in a variably elongated transverse process, or complete rib formation.

\section{3) Vertebral fusion}

Failure of the normal segmentation of the cervical somites during the ages of 3 to 8 weeks results in fusion of the cervical motion segments.

\section{Results}

Among 930 CT scans screened, 377 anomalies were noted in 308 scans $(33.1 \%)$, with more than one anomaly found in 69 scans $(7.4 \%)$. Of the 308 scans with an identified anomaly, 184 (59.7\%) were from male and 124 (40.2.7\%) from female patients with a mean age of 44.2 years (range, $14-78$ years). Two hundred and fifty $(26.8 \%)$ upper cervical anomalies and 127 (13.6\%) subaxial cervical anomalies were identified. Of the 250 upper cervical anomalies, 149 anomalies (53.6\%) including $\mathrm{OA}, \mathrm{PB}, \mathrm{BI}$, os odontoideum, and HRVA have significant clinical implications.

The presence of OC anomalies are one UC (0.1\%) and $13 \mathrm{OA}$ (1.3\%). Gholve et al. [15] classified OA fusion into three zones. Zone 1 involves the anterior atlantal arch in front of the lateral mass, zone 2 involves primarily the lateral processes, and zone 3 involves the posterior arch. In our study, zone 2 involvement was seen in five cases (38.4\%), whereas both zone 1 and 3 involvements were seen in one case (8.3\%); six cases (50\%) showed combined involvement. Other associated anomalies like BI was found in five cases (38.4\%), and three cases of OA (25\%) had AOCA or paracondylar process. PB was documented in four cases $(0.4 \%)$. We divided our BI cases into two types based on the classification put forth by Goel [16]: type 1 patients have fixed atlantoaxial instability, whereas in type 2 the odontoid process and clivus remains anatomically aligned despite the presence of BI. Of the 15 cases (1.6\%) with BI, 12 cases (80\%) are of type 1 and three cases (20\%) are type 2 . Three cases with BI also had PB as an associated anomaly. AOCA or paracondylar process was seen in five cases $(0.5 \%)$, two cases had bilateral AOCA and each of PBA, CDT, and AOA had one case $(0.1 \%)$ noted.

A total of $16(1.7 \%) \mathrm{C} 1$ arch anomalies were noted, of which five had anteroposterior spondyloschisis. When only posterior arch anomalies were characterized according to the classification by Currarino et al. [17], Type A, wherein there is a defect in the midline due to hemi arch failure, was the most common anomaly with four cases. Type B (unilateral) and type C (bilateral) defect each had three cases. One case had only an anterior arch defect. Seventy five cases (8\%) had PP, of which 44 (58.6\%) had complete PP and 31 (41.3\%) had incomplete PP; bilateral complete PP (36\%) was more common in our patients.

C2 arch anomaly was noted in one scan $(0.1 \%)$ which involved the spino-laminar junction with incurving of the bilateral lamina causing spinal canal compromise. 
Odontoid anomalies including ossiculum terminale (one case, $0.3 \%$ ), and os odontoideum (eight cases, $0.8 \%$ ) were evident. Of the eight os odontoideum, six were orthotopic and two were dystopic. One hundred and eight cases (11.6\%) had HRVA.

The subaxial cervical spine between C3-C7 had 127 (13.6\%) anomalies, of which 46 (4.8\%) were DFT; 29 (63\%) of these were bilateral, and 17 (36.9\%) were unilateral. The C6 vertebra was the most common vertebra with DFT (60\% prevalence). Thirty-one patients (3.3\%) had CR, with 17 cases having unilateral and 14 having bilateral CR. We used a modification of the classification proposed by Gruber et al. [18], with type 1 having an elongated transverse process, type 2 extending beyond the transverse process but not articulating with the 1st rib, and type 3 being complete and articulating with the 1st rib. Type 2 (35.4\%) was the most common type observed. Thirty-five (3.7\%) fuzed vertebra were seen, of which seven cases had fusion of more than one segment, and 17 cases (61.9\%) had fusion of the C2-C3 segment. Thirteen cases (1.3\%) of USP were observed, which were more common at the C6 level; five cases had USP at more than 1 level. Two AFC $(0.2 \%)$
Table 1. Summary of clinically significant anomalies of the upper and sub axial cervical spine

\begin{tabular}{lc}
$\begin{array}{l}\text { Variable } \\
\text { No. of occurrence } \\
(\%)\end{array}$ \\
$\begin{array}{l}\text { Upper cervical anomalies (occiput to C2-C3) } \\
\text { Unfused clivus }\end{array}$ \\
\hline Occipito-atlantal assimilation & $13(1.3)$ \\
\hline Platybasia & $4(0.4)$ \\
\hline Basilar invagination & $15(1.6)$ \\
\hline C1 arch anomalies & $16(1.7)$ \\
\hline Ponticulus posticus & $75(8.0)$ \\
\hline Odontoid anomalies & $9(0.9)$ \\
\hline High riding vertebral artery & $108(11.6)$ \\
\hline C2 arch anomaly & $1(0.1)$ \\
\hline Lower cervical anomalies (C3-C7) & $35(3.7)$ \\
\hline Vertebral fusion & $46(4.8)$ \\
\hline Double foramen transversarium & $31(3.3)$ \\
\hline Cervical rib & $2(0.2)$ \\
\hline Abnormal facet complex & $13(1.3)$ \\
\hline Unfused spinous process & \\
\hline
\end{tabular}
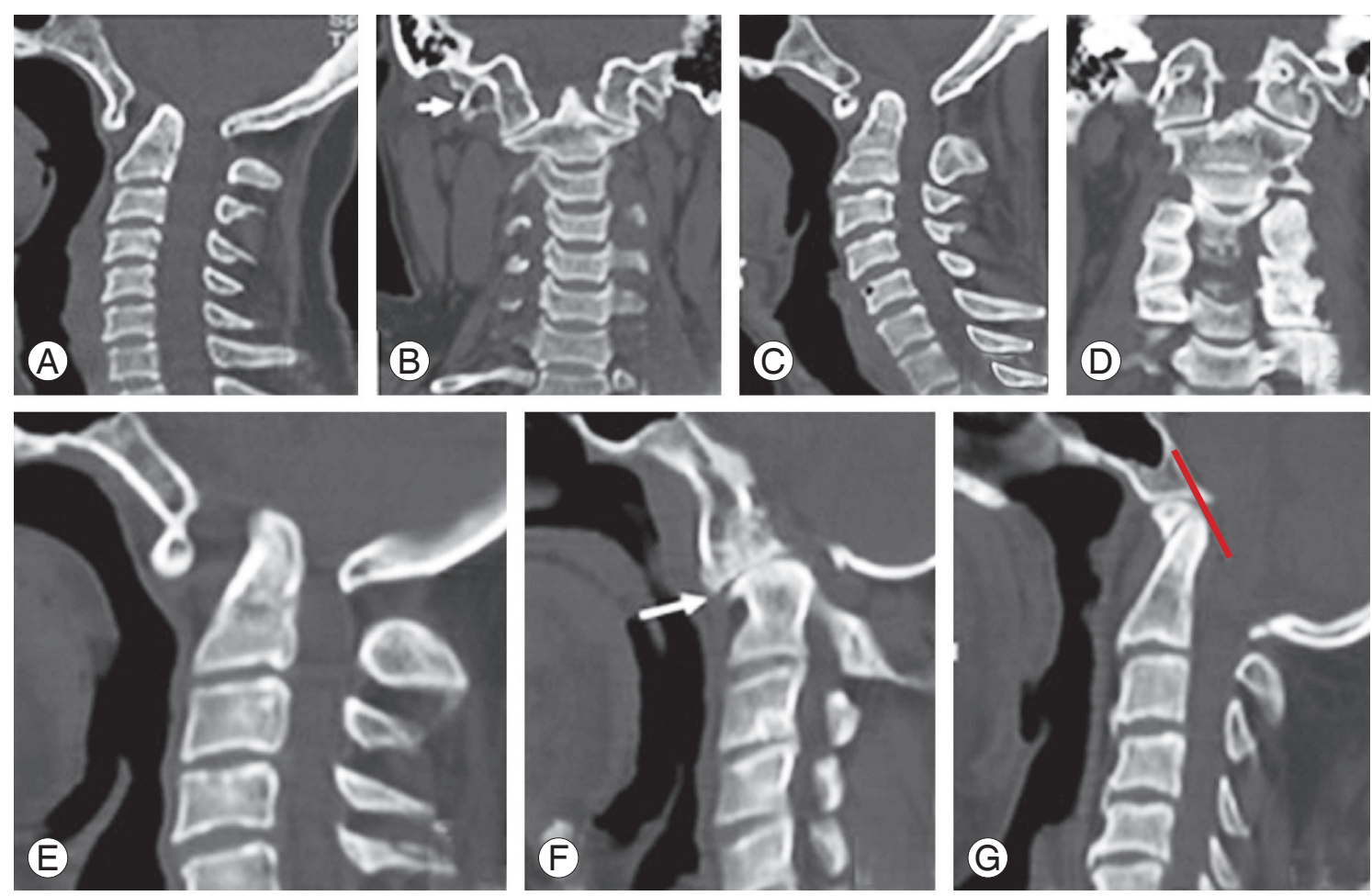

Fig. 2. (A, B) Triple anomaly in a patient; sagittal and coronal view shows complete assimilation of the atlas along with bilateral paracondylar processes (white arrow) and BI. (C, D) Basilar invagination in a patient with C2-C3 fusion and assimilation. (E, F) Type 1 BI with atlantoaxial subluxation. Arrow shows abnormal alignment of the atlanto axial facet. (G) Type 2 BI with a maintained clival-odontoid relationship (red line). BI, basilar invagination. 
were noted. A summary of the clinically significant anomalies of the upper and subaxial cervical spine is mentioned in Table 1.

\section{Discussion}

Anomalies of the cervical spine show a wide range of morphological features, ranging from fuzed vertebra to craniocervical instability. Of the 930 scans screened in the present study, 308 (33.1\%) had at least one congenital anomaly, with 40 of these cases (12.9\%) being of the OC junction.

\section{Occipitocervical region}

This region has a complex developmental process, and hence it is common to find anomalies in this region. Occipital assimilation of the atlas was found in $1.2 \%$ of our cases, which is close to the reported prevalence of $0.08 \%$ $2.76 \%$ [19]. OA is at high risk of developing atlantoaxial instability, especially when there is an associated C2-C3 fusion [15] (Fig. 2). Patients usually become symptomatic during the 3rd to 4 th decade of life. We found paracondylar process along with $\mathrm{BI}$ as an associated anomaly in these patients.

BI was noted in 14 cases; it is an OC anomaly which develops due to abnormally inclined facets of the atlas and axis resulting in progressive slipping of the atlas over
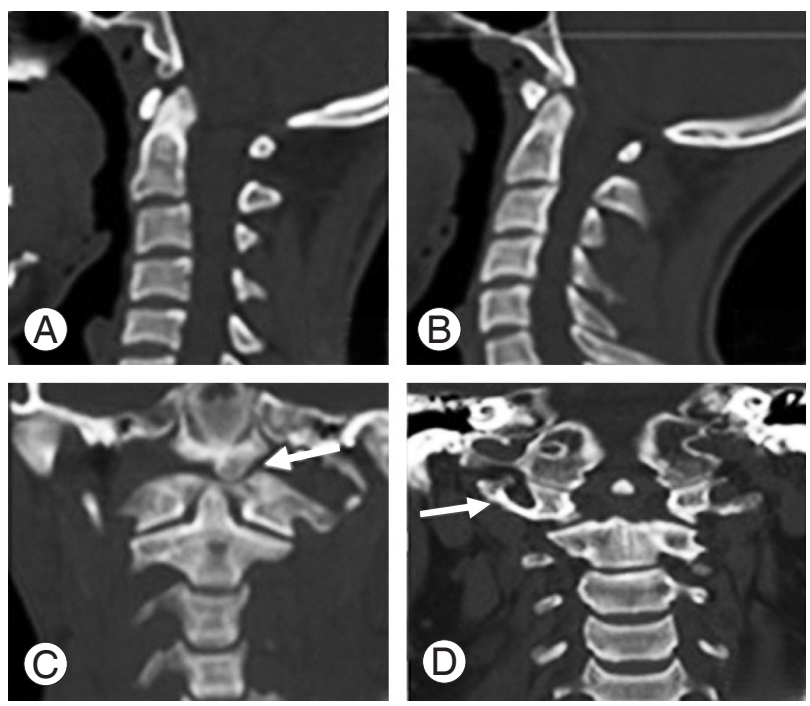

Fig. 3. Occipital vertebra. (A) Prebasioccipital arch. (B, C) Condylus tertius which is articulating with the atlas arch (white arrow). (D) Paracondylar process on the right side (white arrow). the axis accompanied by invagination of the odontoid process into the foramen magnum [20]. Eleven out of the 14 patients in our study had fixed atlantoaxial subluxation and were grouped as type 1 according to the classification of Goel [16]; this classification has a bearing on surgical management as type 1 patients can be treated with OC fusion, whereas in type 2 patients, only decompression of the foramen magnum is sufficient (Fig. 2).

PBA, CDT, basilar processes, and paracondylar processes are collectively referred to as the occipital vertebra. Among these, paracondylar processes is most common, and of the five cases (0.5\%) identified in our study, two had bilateral involvement. PBA and CDT was seen in one case each. Prescher et al. [21] reported accessory articulations in $1 \%-2 \%$ of the cadaveric specimens in their study. These accessory articulations disrupt the normal biomechanics between the occiput and atlas, resulting in mechanical pain and restricted neck movements (Fig. 3).

$\mathrm{C} 1$ anomalies were found in $9.8 \%$ of our cases, of which PP was the most common, being observed in $8 \%$ of cases. Studies in Indian populations have reported variable prevalence rates between $4.3 \%$ and $37.8 \%$ [22,23]. PP has been shown to be associated with cervical pain syndrome, cervicogenic headache, as well as chronic tension type headache [24]. PP can be misidentified as the broad posterior arch of the atlas, leading to inadvertent placement of the $\mathrm{C} 1$ lateral mass screw into it, causing injury to the entrapped vertebral artery in the foramen and resultant torrential bleeding (Fig. 4).

When considering arch defects of the atlas, posterior defects are more common than anterior defects. Combined anterior and posterior defects are the least common, occurring in only $0.3 \%-0.7 \%$ of the population [25]; the present study observed such defects in $0.5 \%$ of cases. Anterior or posterior ring anomalies can often be misread as

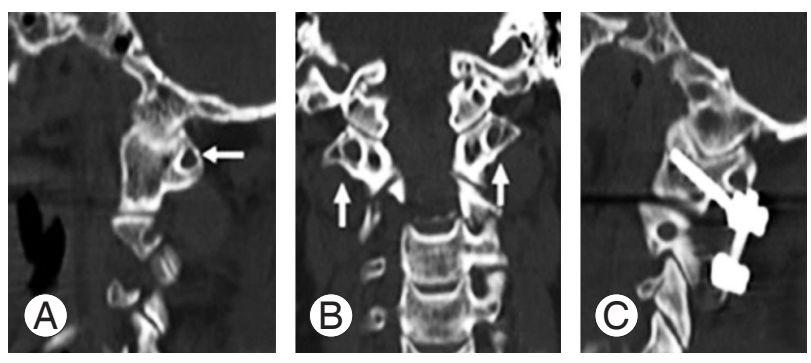

Fig. 4. (A, B) Sagital and coronal images show complete PP (white arrow). (C) Indicates the importance of identifying PP while implanting C1 screws; if PP is misinterpreted as the posterior arch of the atlas, vertebral artery injury is imminent. PP, ponticulus posticus. 

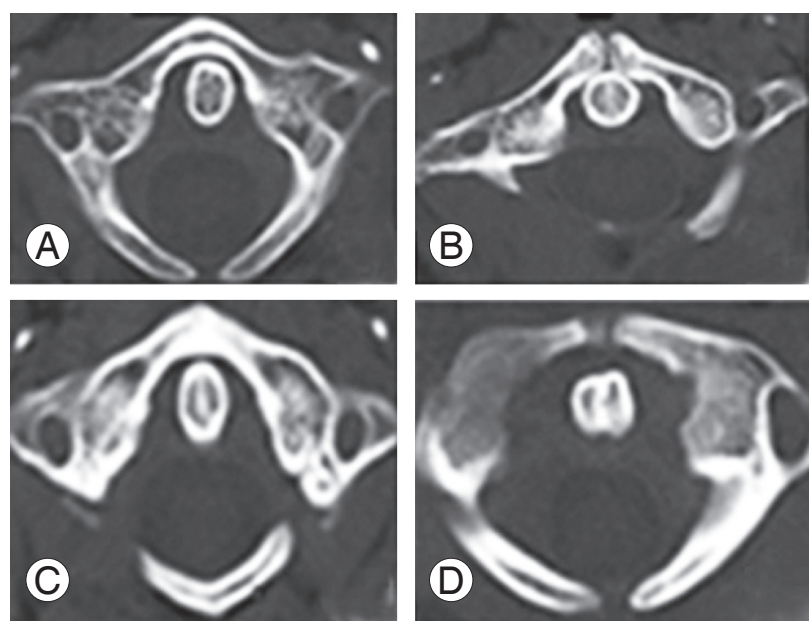

Fig. 5. Various patterns of arch defects of the atlas. (A) Midline; (B) unilateral; (C) bilateral; (D) anterior and posterior (spondyloschisis).
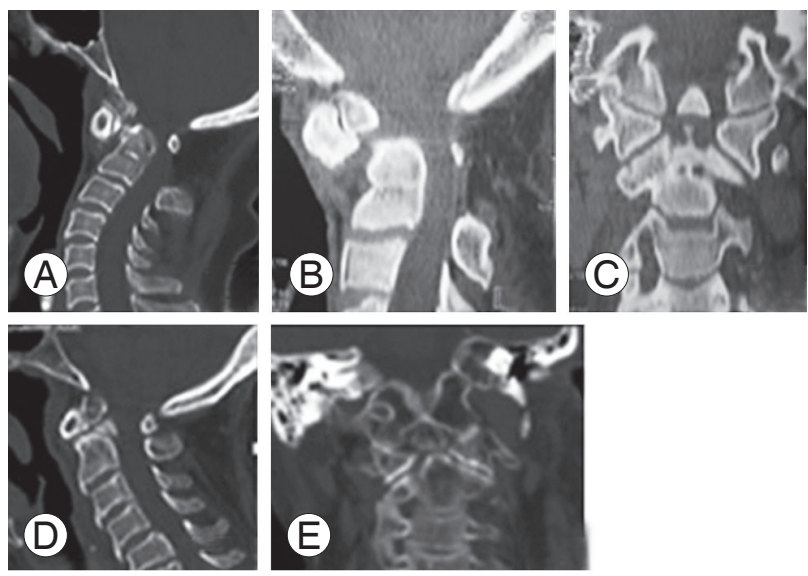

Fig. 6. (A) Dystopic os odontoideum with the odontoid fragment fused to the basion. (B, C) Sagittal and coronal images show orthotopic os odontoideum with round margins and wider clear space between the ossicle and axis to be differentiated from nonunion odontoid (D, E).

fractures on plain films; however, evaluation using CT scan can delineate the difference. $\mathrm{C} 1$ arch defects giving rise to myelopathy have been described in the past [26] (Fig. 5).

Odontoid anomalies were found in nine cases, with os odontoideum being the most common anomaly. Fielding et al. [27] classified os odontoideum as orthotopic (one which moves with the anterior arch of atlas) and dystopic (functionally fuzed to the basion). In os odontoideum, the gap between the free ossicle and the axis usually extends above the level of the superior facets and wide with a smooth edge. This feature is beneficial in distinguishing it from nonunion of the odontoid process (Fig. 6).

Isolated anomalies of the posterior elements of the axis are extremely rare, and there was one such case in which the lamina was invaginating into the canal. $\mathrm{C} 2$ arch de-

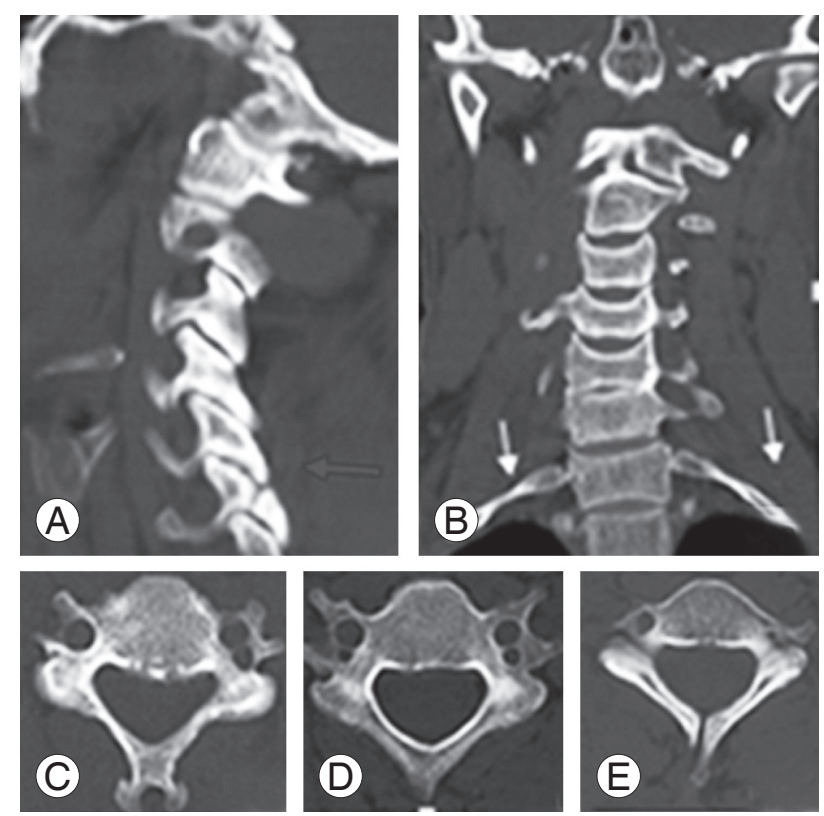

Fig. 7. (A) An abnormal facet complex that mimicks a fracture (blue arrow). (B) Bilateral cervical rib (white arrows). (C) Unilateral DFT. (D) Bilateral DFT. (E) Unfused spinous process. DFT, double foramen transversarium.

fects are often more troublesome in that they must be differentiated from traumatic spondylolisthesis or hangman's fractures. Dysplastic or hypoplastic posterior arches of C2 are often bifid, and can invaginate into the spinal canal causing myelopathy.

\section{Subaxial cervical spine}

In the subaxial cervical spine, 127 anomalies (13.6\%) were noted, of which DFT was the most common anomaly, seen in $4.8 \%$ of scans; the most consistent location of this anomaly was at the level of the C6 vertebra, which is similar to the observation made by Taitz et al. [28]. DFT may indicate an anomalous vertebral artery path, which may be duplicate, bifid or fenestrated [29]. Variations in foramen transversarium can induce an extra-osseous position of the vertebral artery, and lack of knowledge of this anomaly may have disastrous consequences during surgery in the cervical spine.

AFC in the subaxial cervical spine may be misinterpreted as a fracture while evaluating patients with cervical spine injury. Harrop et al. [30] documented the absence of pedicles along with an AFC. In such patients, a thorough physical examination and adequate imaging for the presence of soft-tissue swelling/subluxation is deemed necessary to provide insight into the specific etiology of the 
Table 2. Computed tomography scan sections and the anomalies which can be picked up in that particular section

\begin{tabular}{|c|c|c|}
\hline Axial & Coronal & Sagittal \\
\hline C1 arch abnormalities & Assimilation & Basilar invagination \\
\hline C2 arch abnormalities & $\begin{array}{l}\text { Paracondylar process/accessory occipito-cervical } \\
\text { articulation }\end{array}$ & Condylus tertius \\
\hline Unfused spinous process & Os odontoideum & Prebasioccipital arch \\
\hline Double foramen transversarium & Ossiculum terminale & C2 isthmus \& internal height for high riding vertebral artery \\
\hline Cervical rib & & Vertebral fusion \\
\hline \multirow[t]{6}{*}{ Absence of pedicle } & & Sesamoid of nuchal ligament \\
\hline & & Ponticulus posticus \\
\hline & & Accessory ossicle of atlas \\
\hline & & Abnormal facet complex \\
\hline & & Platybasia \\
\hline & & Unfused clivus \\
\hline
\end{tabular}

condition (i.e., developmental versus traumatic) (Fig. 7).

Thirty-five patients had fuzed cervical motion segments. VF causes alterations in the biomechanics across the motion segments, and results in long lever arms that create abnormal stresses across the vertebrae contributing to unique fracture patterns seen following trivial trauma. C2-C3 was the most common level of fusion observed in the present study. We propose a screening protocol while assessing cervical spine CT scans to identify individual anomalies. The ideal section of a CT scan in which the anomaly can be well appreciated is depicted in Table 2. As the present study was observational in design, it did not review clinical records or symptomatology (symptomatic or asymptomatic) at presentation and treatment of these patients; this remains one potential drawback of the present study. However, we have described the wide spectrum of congenital anomalies which can be encountered in the cervical spine. Considering the varied morphological presentations and their implications on surgical management, the operating surgeon should be aware of these anomalies, and should give due consideration for these anomalies in preoperative planning to avoid undue complications.

\section{Conclusions}

Thirty-three point one percent of scans had at least one congenital anomaly. A wide spectrum of anomalies ranging from simple VF to BI has been reported in this study. Accurate radiologic evaluation is therefore important, as different lesions have markedly different clinical courses, patient management strategies, and prognosis.

\section{Conflict of Interest}

No potential conflict of interest relevant to this article was reported.

\section{References}

1. Hosalkar HS, Sankar WN, Wills BP, Goebel J, Dormans JP, Drummond DS. Congenital osseous anomalies of the upper cervical spine. J Bone Joint Surg Am 2008;90:337-48.

2. Pang D, Thompson DN. Embryology and bony malformations of the craniovertebral junction. Childs Nerv Syst 2011;27:523-64.

3. Klimo P Jr, Rao G, Brockmeyer D. Congenital anomalies of the cervical spine. Neurosurg Clin N Am 2007;18:463-78.

4. Tambawala SS, Karjodkar FR, Sansare K, et al. Prevalence of ponticulus posticus on lateral cephalometric radiographs, its association with cervicogenic headache and a review of literature. World Neurosurg 2017;103:566-75.

5. Soni P, Sharma V, Sengupta J. Cervical vertebrae anomalies-incidental findings on lateral cephalograms. Angle Orthod 2008;78:176-80.

6. Zibis AH, Mitrousias V, Baxevanidou K, Hantes M, Karachalios T, Arvanitis D. Anatomical variations of the foramen transversarium in cervical vertebrae: 
findings, review of the literature, and clinical significance during cervical spine surgery. Eur Spine J 2016;25:4132-9.

7. McCall T, Coppens J, Couldwell W, Dailey A. Symptomatic occipitocervical paracondylar process. J Neurosurg Spine 2010;12:9-12.

8. Muthu SK, Cox S, Gunawardena WJ, Balakrishnan G. Anteroposterior spondyloschisis of the atlas: two case reports and literature review. Emerg Radiol 2007;13:337-40.

9. Paraskevas GK, Raikos A, Martoglou S, Ioannidis O. Sesamoid ossicles within the nuchal ligament: a report of two cases and review of the literature. J Radiol Case Rep 2011;5:22-9.

10. Robles LA. True oblique axis fracture associated with congenital anomalies of the upper cervical spine: case report of an unusual fracture pattern. Surg Neurol Int 2017;8:7.

11. Yeom JS, Buchowski JM, Park KW, Chang BS, Lee $\mathrm{CK}$, Riew KD. Undetected vertebral artery groove and foramen violations during $\mathrm{C} 1$ lateral mass and C2 pedicle screw placement. Spine (Phila Pa 1976) 2008;33:E942-9.

12. Chamberlain WE. Basilar impression (platybasia): a bizarre developmental anomaly of the occipital bone and upper cervical spine with striking and misleading neurologic manifestations. Yale J Biol Med 1939;11:487-96.

13. Selby S, Garn SM, Kanareff V. The incidence and familial nature of a bony bridge on the first cervical vertebra. Am J Phys Anthropol 1955;13:129-41.

14. Schilling J, Schilling A, Suazo Galdames I. Ponticulus posticus en el Arco Posterior del Atlas, Analisis de su Prevalencia en Pacientes Asintomaticos. Int J Morphol 2010;28:317-22.

15. Gholve PA, Hosalkar HS, Ricchetti ET, Pollock AN, Dormans JP, Drummond DS. Occipitalization of the atlas in children: morphologic classification, associations, and clinical relevance. J Bone Joint Surg Am 2007;89:571-8.

16. Goel A. Basilar invagination, Chiari malformation, syringomyelia: a review. Neurol India 2009;57:23546.

17. Currarino G, Rollins N, Diehl JT. Congenital defects of the posterior arch of the atlas: a report of seven cases including an affected mother and son. AJNR Am J Neuroradiol 1994;15:249-54.

18. Gruber W. Vortauschung einer Fractur der ersten Rippe durch eine kurze supernumerare Rippe. Virchows Archiv 1865;32:108-10.

19. Macalister A. Notes on the development and variations of the Atlas. J Anat Physiol 1893;27:519-42.

20. Kothari M, Goel A. Transatlantic odonto-occipital listhesis: the so-called basilar invagination. Neurol India 2007;55:6-7.

21. Prescher A, Brors D, Adam G. Anatomic and radiologic appearance of several variants of the craniocervical junction. Skull Base Surg 1996;6:83-94.

22. Sharma V, Chaudhary D, Mitra R. Prevalence of ponticulus posticus in Indian orthodontic patients. Dentomaxillofac Radiol 2010;39:277-83.

23. Mudit G, Srinivas K, Satheesha R. Retrospective analysis of ponticulus posticus in Indian orthodontic patients: a lateral cephalometric study. Ethiop J Health Sci 2014;24:285-90.

24. Koutsouraki E, Avdelidi E, Michmizos D, Kapsali SE, Costa V, Baloyannis S. Kimmerle's anomaly as a possible causative factor of chronic tension-type headaches and neurosensory hearing loss: case report and literature review. Int J Neurosci 2010;120:236-9.

25. Shikata J, Yamamuro T, Mikawa Y, Iida H, Kobori M. Atlanto-axial subluxation in Down's syndrome. Int Orthop 1989;13:187-92.

26. Weng C, Wang LM, Wang WD, Tan HY. Bipartite atlas with os odontoideum and synovial cyst: case report and review literature. Spine (Phila Pa 1976) 2010;35:E568-75.

27. Fielding JW, Hensinger RN, Hawkins RJ. Os odontoideum. J Bone Joint Surg Am 1980;62:376-83.

28. Taitz C, Nathan H, Arensburg B. Anatomical observations of the foramina transversaria. J Neurol Neurosurg Psychiatry 1978;41:170-6.

29. Hashimoto H, Ohnishi H, Yuasa T, Kawaguchi S. Duplicate origin of the vertebral artery: report of two cases. Neuroradiology 1987;29:301-3.

30. Harrop JS, Jeyamohan S, Sharan A, et al. Acute cervical fracture or congenital spinal deformity? J Spinal Cord Med 2008;31:83-7. 